\title{
New species of Galatheidae (Crustacea: Anomura: Galatheoidea) from volcanic seamounts off northern New Zealand
}

\author{
A.L. Vereshchaka \\ Institute of Oceanology, Russian Academy of Sciences, Nakhimovsky Prospekt 36, Moscow, 117997, Russia. \\ E-mail: alvereshchaka@yahoo.com
}

\begin{abstract}
Two new species of Munida (M. gordoni and M. grieveae) and one new species of Agononida (A. nielbrucei) are described from volcanic seamounts off northern New Zealand (RV 'Tangaroa', National Institute of Water and Atmospheric Research [NIWA], New Zealand). Description of new species and preliminary examination of NIWA collections reveal unusually high endemism of volcanic seamount populations of Galatheidae.
\end{abstract}

\section{INTRODUCTION}

Extensive research on the fauna of volcanic seamounts, both with and without hydrothermal activity, has been undertaken in recent years. General aspects of faunistic composition, community structure, fisheries, and conservation were considered in Keating et al. (1987), Rogers (1994), Vereshchaka (1995), and many other studies. In the Southern Pacific including the waters off New Zealand this research has mainly focused on faunistic composition and fisheries implications (Clark et al., 1999; Rowden et al., 2002). This focus is a part of general efforts of the marine biological community to investigate the marine biodiversity and biology of hydrothermal vents. During recent years, NIWA, New Zealand, has initiated extensive research of the surrounding waters using the RV 'Tangaroa'. These expeditions contribute to several important general trends in modern marine biology:

1. Analysis of the fauna of the chemosynthesis-based ecosystems including volcanic seamounts and estimation of the degree of endemism of this fauna.

2. Studies of the general biodiversity of the World Ocean, with many efforts combined under the programme 'Census of Marine Life'. This, in turn, will favour an important regional task.

3. Creation of the faunal list for the waters around New Zealand. Being geographically distant from most of well-explored areas, New Zealand is a region with a poorly known fauna and a high degree of endemism and presenting a challenge to any biologist.

One of the most visible and important groups of animals associated with seamounts are decapod crustaceans, particularly, the squatlobsters of the family Galatheidae. This family comprises mostly benthic (when adult) comparatively large (total length usually $1 \mathrm{~cm}$ and more) lobster-like animals. This family presently contains 28 genera, among which the genus Munida Leach, 1820 is one of the most diverse with 156 species in the IndoPacific region alone. The genus Agononida Baba \& de Saint Laurent, 1996 with 22 species from the Indo-Pacific is morphologically very similar to Munida but can be separated from the former Munida sensu lato mainly by the absence of the male gonopods on the first abdominal somite.

\section{Abbreviations, measurements and terminology}

Abbreviations: Cp, carapace; R, rostrum; Ab, abdomen; A I-II, antennule and antenna, respectively; Mxp, maxillipeds; P I-IV, pereopods I-IV; NIWA, National Institute of Water and Atmospheric Research, New Zealand.

Measurements: follows Vereshchaka (2000, measurements illustrated in detail-Figure 1). Carapace postorbital length measured along dorsal midline from the base of the $\mathrm{R}$ to posterior midpoint of $\mathrm{Cp}$; width was measured in dorsal view across the widest part, posterior cardiac region.

Terminology: follows Baba (1988) and Macpherson (2000) with two exceptions: according to the modern terminology, fixed protrusions of $\mathrm{Cp}, \mathrm{Ab}$ and appendages are called 'teeth' instead of 'spines' to distinguish them from articulated structures; the term 'precervical lateral' will be used instead of 'lateral epigastric' for the teeth of the lateral margin of $\mathrm{Cp}$ anterior to the cervical groove; 'precervical lateral' relates better to widely used term, 'postcervical lateral', used for the teeth of the lateral margin of $\mathrm{Cp}$ posterior to the cervical groove.

\section{SYSTEMATICS}

GALATHEIDAE Samouelle, 1819

Agononida Baba \& de Saint Laurent, 1996 Agononida nielbrucei sp. nov.

(Figure 1A-F, Table 1)

\section{Material}

Holotype: Tangaroa Expedition Station 0107/01 (19 May 2001, 35 $44.51-44.35^{\prime} \mathrm{S} 178^{\circ} 30.20-29.75^{\prime} \mathrm{E}, 470-260 \mathrm{~m}$, scoria rubble), one ovigerous female Cp length $11.1 \mathrm{~mm}$, held in NIWA, catalogue no. H-879, NIWA 4066.

\section{Diagnosis}

Carapace with sharp spiniform R, subraorbital teeth 0.7 length of $\mathrm{R}$, front margin nearly transverse, one pair of 


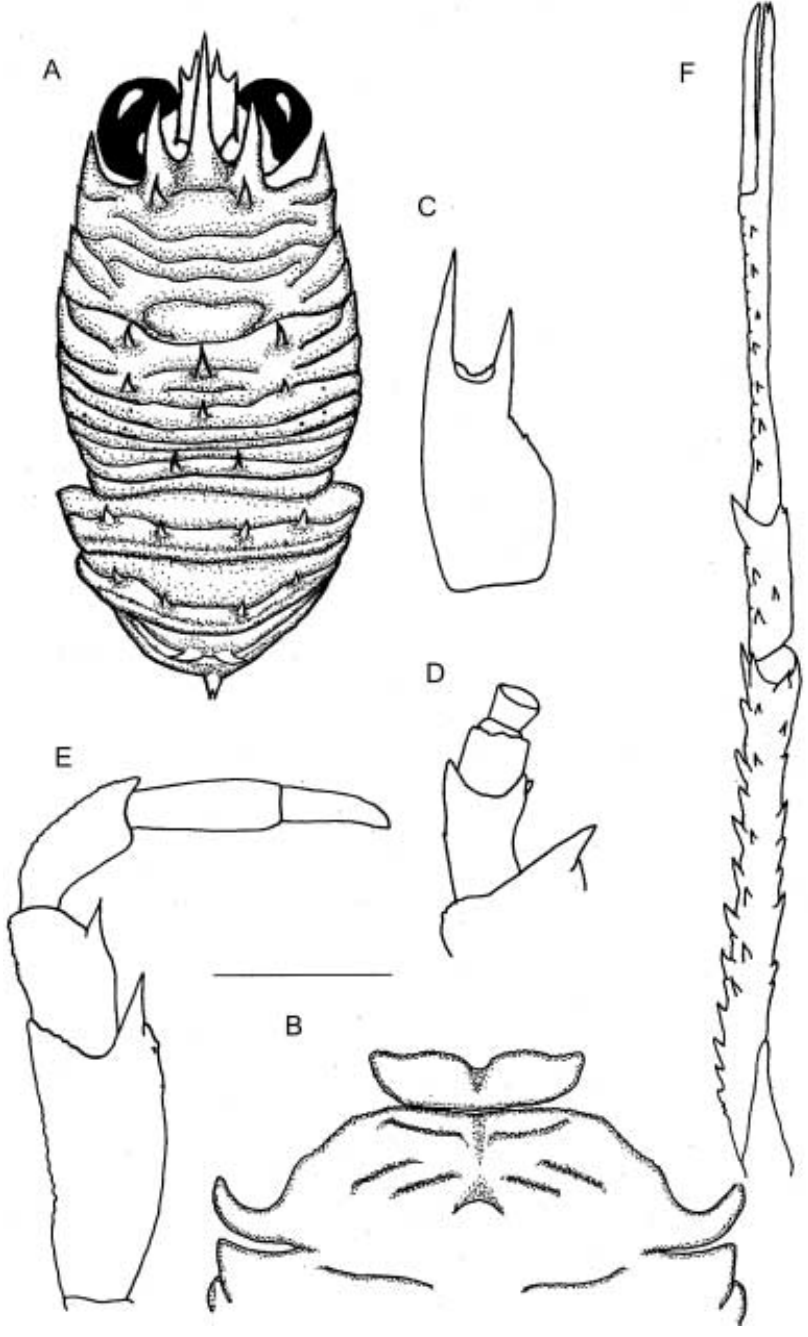

Figure 1. Agononida nielbrucei sp. nov. (A) Carapace and Ab (dorsal view); (B) anterior thoracic sternites (ventral view); (C) basal segment of left A I (ventral view); (D) peduncle of right A II (ventral view); (E) right Mxp III (ventral view); (F) right $\mathrm{P}$ I (dorsal view). Setae not shown. Scale bar: A, F, 6 mm; B-E, $2 \mathrm{~mm}$.

teeth in epigastric region; three pairs of very small lateral postcervical teeth, six cardiac teeth in two rows posterior to cervical groove, one pair of teeth on posterior transverse $\mathrm{Cp}$ ridge; $\mathrm{Ab}$ with four teeth on anterior ridge of 2nd segment, four teeth on anterior ridge of 3rd segment, two teeth on anterior ridge and one medial tooth on posterior ridge of 4 th segment; A I basal segment without lateral teeth (two minute barbs only), mesial terminal tooth longer than lateral; A II lst segment with terminal tooth not reaching end of 2nd segment, 2nd segment with two terminal barbs; Mxp III with single long distal tooth on flexor margin of ischium and single medial tooth on flexor margin of merus; P I slender, both fingers without proximal teeth, fixed finger with two distal teeth.

\section{Description}

Rostrum with several scattered medium-sized setae; anterior lateral precervical tooth long (Figure 1A), reaching middle of supraorbital tooth, posterior tooth very small; epigastric teeth large. Lateral postcervical teeth on each side of $\mathrm{Cp}$ behind cervical groove barb-like and somewhat blunt, one pair of indistinct lateral barbs posterior to 3rd pair of teeth; three posterior cardiac teeth smaller than anterior teeth and positioned just behind them, cardiac region with several irregular barbs posterior to cardiac teeth; two teeth on posterior transverse $\mathrm{Cp}$ ridge sharp and well-developed. Carapace with arcuate, mostly granulate ridges and striae, covered with irregular medium-sized setae. Thoracic sternites as shown in Figure 1B, with slight transverse, granulate carinae; tergites 2-4 of $\mathrm{Ab}$ with three granulate, transverse carinae separated by two inconspicuous striae.

Cornea reaching end of subraorbital teeth. Antennule I basal segment with two small lateral barbs, mesial terminal tooth about 1.5 times longer than lateral tooth (Figure 1C). Antennule II lst segment bearing terminal tooth barely reaching middle of 2nd segment, 2nd segment with very small terminal barbs (Figure 1D).

Distal tooth of Mxp III ischium reaching midlength of merus, medial tooth of merus reaching end of merus (Figure 1E). Pereopod I (Figure 1F) 3.8 times as long as Cp, palm (without fingers) twice as long as fingers. Propodi of Pp II-IV each with eight spines on flexor margin, dactyl of Pp II with nine movable spines on flexor margin, dactyli of Pp III-IV each with eight movable spines on flexor margin.

Other measurements presented in Table 1.

Remarks

Although the male of Agononida nielbrucei sp. nov. remains unknown, the placement of this species in Agononida is beyond any doubt. The unique combination of: several teeth reduced to barbs (4th pair of lateral postcervical teeth on $\mathrm{Cp}$, lateral teeth on A I basal segment) and the dorsal armature of $\mathrm{Cp}$ and $\mathrm{Ab}$ allow easy separation of a new species from all other species of the genus.

Other characters separate A. nielbrucei from other IndoPacific species of Agononida:

1. The presence of a posterior tooth on the $4 \mathrm{th} \mathrm{Ab}$ somite distinguishes $A$. nielbrucei sp. nov. from $A$. laurentae (Macpherson, 1994), A. ocyrhoe (Macpherson, 1994), A. pilosimanus (Baba, 1969), A. sabatesae (Macpherson, 1994), A. tenuipes (Miyake \& Baba, 1967), and $A$. sphecta (Macpherson, 1994).

2. The comparative length of the supraorbital teeth distinguishes $A$. nielbrucei sp. nov. from A. longispinata (Baba, 1988) (in the latter species the the supraorbital teeth overlap the $\mathrm{R}$ ).

3. The comparative length of the process of lst segment of A II distinguishes $A$. nielbrucei sp. nov. from $A$. andrewi (Macpherson, 1994), A. incerta (Henderson, 1888), A. fortiantennata (Baba, 1988), A. variabilis (Baba, 1988), A. marini (Macpherson, 1994), A. emphereia (Macpherson, 1997), A. callirrhoe (Macpherson, 1994), (all these species have the process of 1st segment considerably exceeding end of A II peduncle).

4. The new species differs from A. soelae (Baba, 1986 (in Baba et al., 1986)) by the absence of protogastric spines.

5. The new species differs from A. normani (Henderson, 1885) - by the absence of transverse row of minute teeth in cardiac region of $\mathrm{Cp}$; and from A. squamosa (Henderson, 1885), A. similis (Baba, 1988), and A. analoga (Macpherson, 1993) - by the presence of posterior row of cardiac teeth on Cp. 

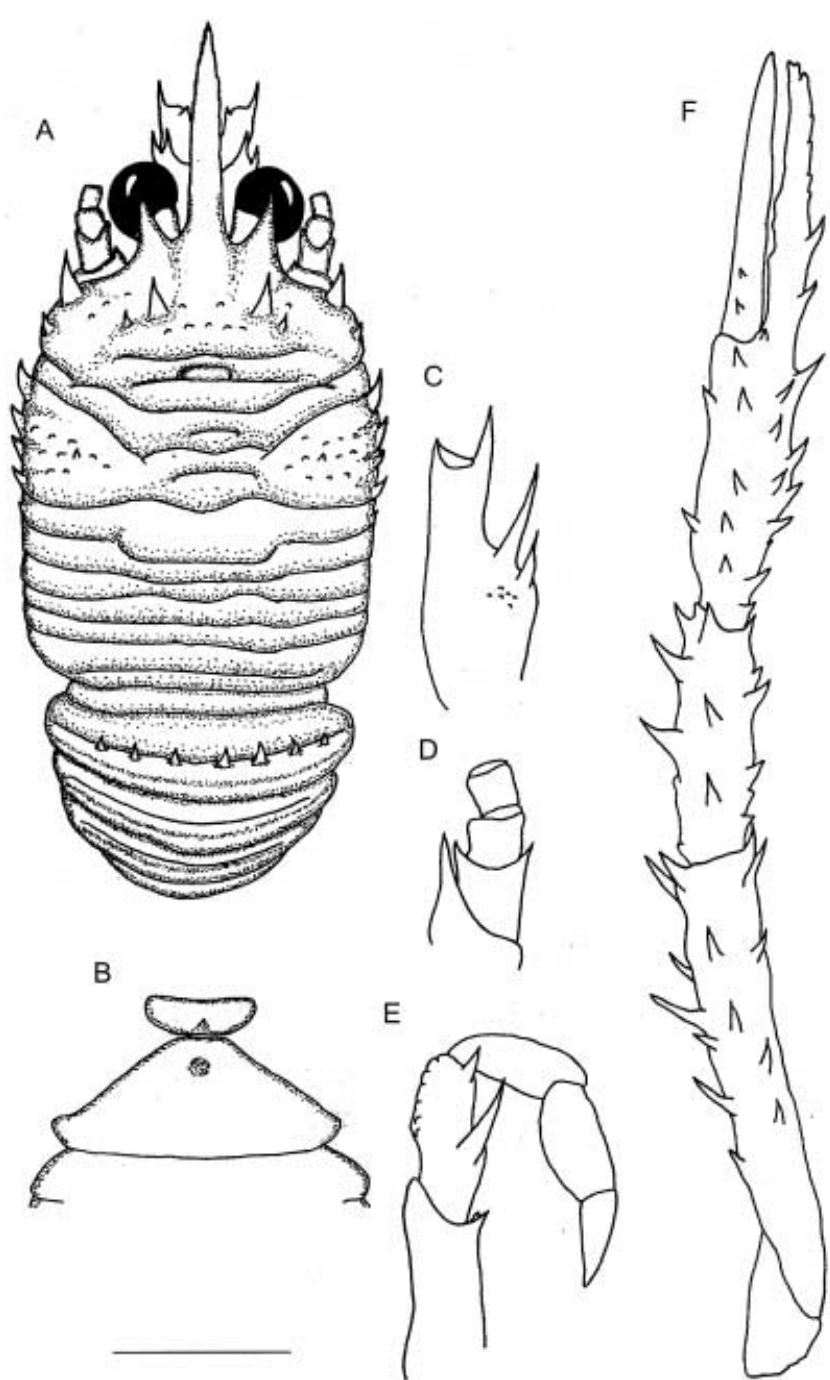

Figure 2. Munida gordoni sp. nov. (A) Carapace and Ab (dorsal view); (B) anterior thoracic sternites (ventral view); (C) basal segment of left A I (ventral view); (D) peduncle of right A II (ventral view); (E) right Mxp III (ventral view); (F) right $\mathrm{P} I$ (dorsolateral view). Setae not shown. Scale bar: A, F, $4 \mathrm{~mm}$; B-E, $2 \mathrm{~mm}$.

This new species is the first of the genus found in the waters off New Zealand.

\section{Etymology}

Named after Dr Niel Bruce, well-known carcinologist (NIWA), who arranged my visit to New Zealand.

\author{
Munida Leach, 1820 \\ Munida gordoni sp. nov.
}

(Figure 2A-F; Tables 1 \& 2)

\section{Material}

Holotype: Tangaroa Expedition Station 0107/326 (off Wairarapa coast, 24 May 2001, 41 $35.45-34.88^{\circ} \mathrm{S}$ $175^{\circ} 46.39-47.23^{\prime} \mathrm{E}, 1400-1000 \mathrm{~m}$, mud), one ovigerous female Cp length $11.0 \mathrm{~mm}$, held in NIWA, catalogue no. H-880, NIWA 4065.

\section{Diagnosis}

Carapace with sharp spiniform $\mathrm{R}$, subraorbital teeth 0.4 length of $\mathrm{R}$, front margin oblique, two pairs of teeth on epigastric region, five pairs of lateral postcervical teeth; single very small postcervical tooth on each branchial region in addition to granules, cardiac region and posterior transverse $\mathrm{Cp}$ ridge without teeth; $\mathrm{Ab}$ with seven teeth on anterior ridge of 2nd segment, 3rd and 4th segments unarmed; A I basal segment with two lateral teeth (distal longer), mesial terminal tooth shorter than lateral, a few barbs on ventral surface proximal and mesial to lateral teeth; A II with 1st segment bearing terminal tooth exceeding 2nd segment, 2nd segment with two subequal terminal teeth, 3rd segment without minute terminal tooth; Mxp III with two small unequal distal teeth on flexor margin of ischium, with longer mesial and shorter distal tooth on flexor margin of merus; fixed fingers of P I bearing 2-3 teeth in proximal part, dactyl of P I bearing two teeth in proximal part; flexor margin of dactyli of P III-IV with movable spines on entire length except proximal $1 / 10$.

\section{Description}

Rostrum with irregular lateral barbs and several scattered dorsal medium-sized setae; lateral precervical teeth both well defined and sharp, anterior three times as large as posterior; mesial epigastric teeth twice as large as lateral (Figure 2A), epigastric region covered with granules in addition to teeth. Lateral postcervical teeth welldefined, decreasing in size posteriorly; postcervical tooth barb-like, hardly distinguishable from about ten granules on branchial region. Carapace with arcuate, very slightly granulate ridges and striae, covered with irregular medium-sized setae. Thoracic sternites as shown in Figure 2B, no prominent transverse granulate carinae. Teeth on 2nd segment of $\mathrm{Ab}$ subequal, each of $2 \mathrm{nd}-4$ th segments of $\mathrm{Ab}$ with two transverse ridges separated by single striae.

Cornea reaching end of subraorbital teeth. Distal lateral tooth of A I basal segment twice as long as proximal, lateral terminal tooth three times as long as mesial (Figure 2G). Antennule II lst segment bearing terminal tooth reaching middle of 3rd segment; 2 nd segment with sharp terminal teeth reaching end of tooth of lst segment (Figure 2D).

Maxilliped III with larger distal tooth of ischium two times longer than shorter tooth, medial tooth of merus reaching end of same segment and 2.5 times as long as terminal tooth (Figure 2E). Pereopod I (Figure 2F) three times as long as Cp, palm (without fingers) as long as fingers, dactyl with two proximal teeth on both chelae, fixed finger barbate medially and distally, with two proximal teeth in right chela and three proximal teeth in left chela. Pereopod II missing. Propodi of P III - IV each with five spines on flexor margin, dactyli of P III-IV with 16 movable spines on flexor margin.

Other measurements presented in Table 1.

Remarks

See remarks under Munida grieveae sp. nov.

\section{Etymology}

Named after Dr Dennis Gordon (NIWA), broadly educated naturalist, and expert in many groups of marine and terrestrial organisms. 


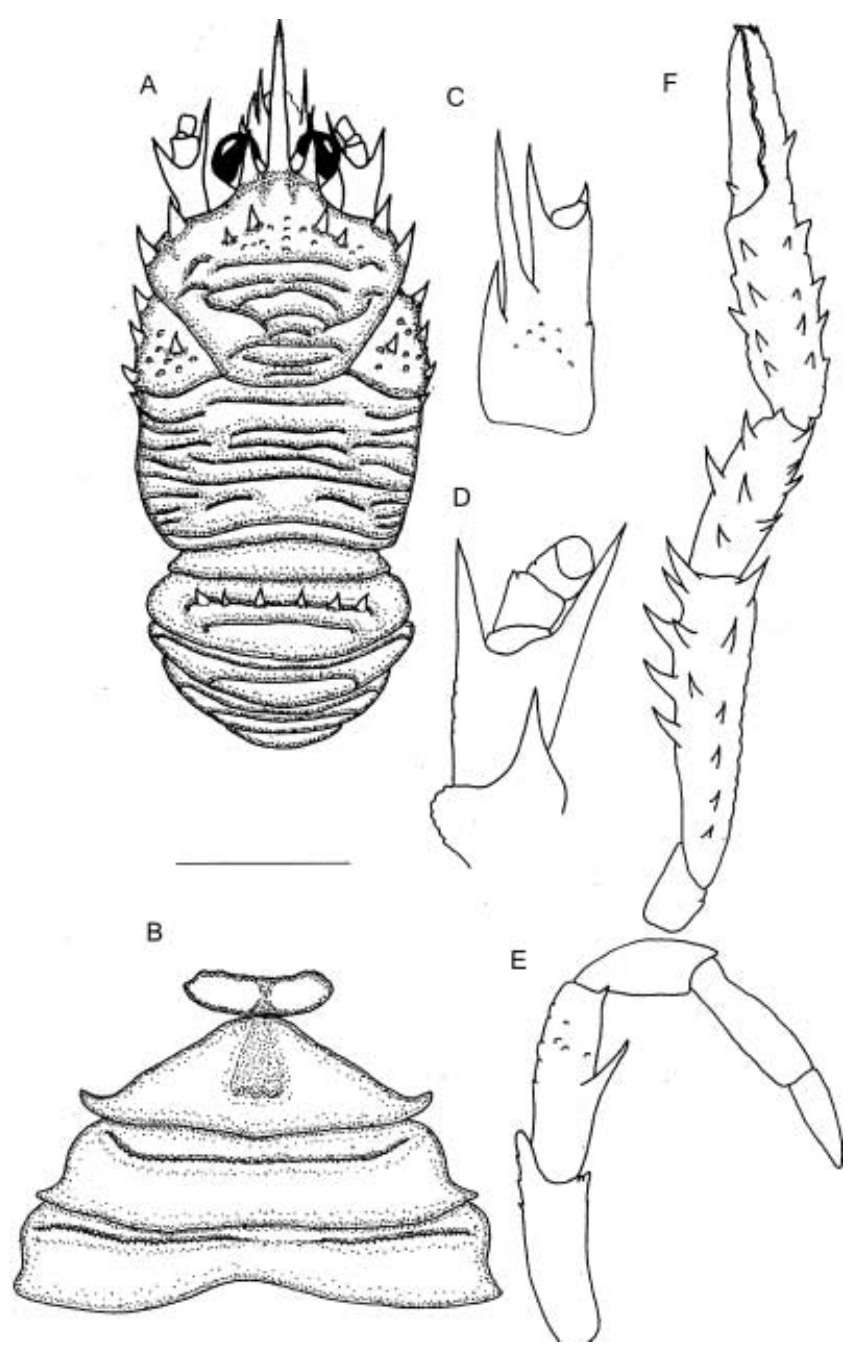

Figure 3. Munida grieveae sp. nov. (A) Carapace and Ab (dorsal view); (B) anterior thoracic sternites (ventral view); (C) basal segment of right A I (ventral view); (D) peduncle of right A II (ventral view); (E) right Mxp III (ventral view); (F) right $\mathrm{P}$ I (dorsal view). Setae not shown. Scale bar: A,F, $5 \mathrm{~mm}$; B-E, $2 \mathrm{~mm}$.

Munida grieveae sp. nov.

(Figure 3A-F, Tables 1 \& 2)

\section{Material}

Holotype: Tangaroa Expedition Station 0107/228 (24 May 2001, $36^{\circ} 08.36-08.57^{\prime} \mathrm{S} \quad 178^{\circ} 11.77-11.50^{\prime} \mathrm{E}, \quad 977-$ $655 \mathrm{~m}$, mud), one ovigerous female Cp length $11.0 \mathrm{~mm}$, held in NIWA, catalogue no. H-881, NIWA 4064.

\section{Diagnosis}

Carapace with sharp spiniform $\mathrm{R}$, subraorbital teeth reaching 0.3 length of $\mathrm{R}$, front margin oblique, two pairs of teeth on epigastric region, five pairs of lateral postcervical teeth 3rd of which rudimentary; single well defined postcervical tooth on each branchial region in addition to granules, cardiac region and posterior transverse $\mathrm{Cp}$ ridge lacking teeth; posterior thoracic sternites each with a well defined granulate carina; Ab with six teeth on anterior ridge of 2nd segment, 3rd and 4th segments unarmed; A I basal segment with two lateral teeth (distal longer), mesial terminal tooth shorter than lateral, and few barbs on ventral surface proximal and mesial to lateral teeth; A II with 1st segment bearing terminal tooth not exceeding 2nd segment, 2nd segment with two unequal terminal teeth, mesial tooth longer and exceeding peduncle, $3 \mathrm{rd}$ segment without minute terminal tooth; Mxp III with two small unequal distal teeth on flexor margin of ischium, with longer mesial and shorter distal tooth on flexor margin of merus; fixed finger and dactyl of P I each bearing single proximal tooth, fixed finger bearing two distal teeth; movable spines on flexor margin of P III-IV dactyli occupy entire length except proximal $10 \%$.

\section{Description}

Rostrum with irregular lateral barbs and several scattered dorsal medium-sized setae; lateral precervical teeth subequal, both well defined and sharp; mesial epigastric teeth twice as large as lateral (Figure 3A), epigastric region covered with granules in addition to teeth. First2nd and 4th-5th lateral postcervical teeth well-defined, decreasing in size posteriorly; postcervical tooth sharp, much more conspicuous than ten granules on branchial region. Carapace with arcuate, slightly granulate ridges and striae, covered with irregular medium-sized setae. Thoracic sternites as shown in Figure 3B, transverse granulate carinae almost joined in middle of sternites. Teeth on 2nd segment of $\mathrm{Ab}$ subequal, each of 2nd-4th segments of Ab with two transverse carinae separated by single striae.

Cornea barely reaching end of subraorbital teeth. Distal lateral tooth of A I basal segment three times as long as proximal, lateral terminal tooth three times as long as mesial (Figure 3C). First segment of A II with terminal tooth reaching 2nd segment; 2nd segment with sharp terminal teeth, lateral spine reaching end of 3rd segment, mesial tooth exceeding peduncle (Figure 3D).

Appendages dorsally covered with dense setose setae. Maxilliped III with larger distal tooth of ischium two times longer than shorter tooth, medial tooth of merus not reaching end of same segment and five times as long as terminal tooth (Figure 3E). Pereoped I (Figure 3F) 2.5 times as long as $\mathrm{Cp}$, palm (without fingers) slightly longer than fingers, both fingers barbate along lateral margins. Propodi of P II-IV with eight, 5-6 and five movable spines on flexor margin, respectively; dactyli of P II-IV with 15-16, 13, and 12 movable spines on flexor margin, respectively.

Other measurements presented in Table 1.

\section{Remarks}

The two new species of Munida found off New Zealand and described here, M. gordoni and $M$. grieveae, are close to M. chathamensis Baba, 1974 described from the same geographical area earlier (Baba, 1974). All three species share the following set of characters: (i) armature of Cp: two pairs of precervical and five pairs of postcervical lateral teeth, two pairs of epigastric teeth and one pair of postcervical branchial teeth/barbs, no other Cp teeth; (ii) armature of $\mathrm{Ab}$ : six dorsal (rarely +1 additional asymmetrical in $M$. chathamensis and M. gordoni) spines on 2nd segments and no teeth on other segments; (iii) armature of basal segment of A I: two lateral spines, distal longer 
Table 1. Basic measurements, $m m$, of Agononida nielbrucei sp.nov., Munida gordoni sp. nov., and Munida grieveae $s p$. nov.

\begin{tabular}{|c|c|c|c|c|c|c|}
\hline \multirow[t]{2}{*}{ Body part } & \multicolumn{2}{|c|}{ A. nielbrucei } & \multicolumn{2}{|c|}{ M. gordoni } & \multicolumn{2}{|c|}{ M. grieveae } \\
\hline & Length & Width & Length & Width & Length & Width \\
\hline $\mathrm{Cp}$ & 11.1 & 10.7 & 11.0 & 8.4 & 11.7 & 9.0 \\
\hline $\mathrm{R}$ & 4.3 & 1.1 & 5.0 & 0.9 & 5.1 & 0.9 \\
\hline Subraocular spines & 2.7 & 0.8 & 2.6 & 0.6 & 1.5 & 0.5 \\
\hline Ischium of P I & 3.7 & 1.5 & 3.2 & 1.5 & 3.8 & 1.8 \\
\hline Merus of P I & 17.7 & 1.5 & 11.0 & 1.7 & 11.9 & 2.3 \\
\hline Carpus of P I & 5.1 & 1.5 & 5.8 & 1.8 & 5.6 & 2.4 \\
\hline Palm without fingers of P I & 11.4 & 1.0 & 6.9 & 1.9 & 7.2 & 2.4 \\
\hline Fixed finger of P I & 6.5 & 0.6 & 6.7 & 1.0 & 6.4 & 0.9 \\
\hline Dactyl of P I & 6.3 & 0.6 & 6.7 & 0.8 & 6.4 & 1.0 \\
\hline Ischium of P II & 2.7 & 1.5 & - & - & 2.2 & 1.2 \\
\hline Merus of P II & 11.1 & 1.5 & - & - & 9.4 & 1.1 \\
\hline Carpus of P II & 2.7 & 1.2 & - & - & 2.5 & 1.3 \\
\hline Propodus of P II & 6.9 & 1.0 & - & - & 5.9 & 0.9 \\
\hline Dactyl of P II & 3.9 & 0.8 & - & - & 3.9 & 0.7 \\
\hline Ischium of P III & 1.8 & 1.5 & 1.7 & 1.0 & 1.9 & 1.2 \\
\hline Merus of P III & 10.3 & 1.5 & 7.5 & 1.2 & 7.9 & 1.4 \\
\hline Carpus of P III & 2.8 & 1.1 & 2.5 & 1.3 & 2.8 & 1.5 \\
\hline Propodus of P III & 7.1 & 1.0 & 6.1 & 0.9 & 5.8 & 0.8 \\
\hline Dactyl of P III & 3.9 & 0.7 & 4.6 & 0.8 & 4.0 & 0.7 \\
\hline Ischium of P IV & 2.3 & 1.2 & 1.5 & 1.0 & 3.8 & 1.0 \\
\hline Merus of P IV & 8.6 & 1.4 & 6.5 & 1.2 & 5.4 & 1.5 \\
\hline Carpus of P IV & 3.0 & 1.4 & 2.6 & 1.3 & 2.9 & 1.4 \\
\hline Propodus of P IV & 6.7 & 1.0 & 6.1 & 0.9 & 5.6 & 1.0 \\
\hline Dactyl of P IV & 3.9 & 0.7 & 4.1 & 0.8 & 3.8 & 0.8 \\
\hline
\end{tabular}

-, no data.

than proximal, two terminal spines, lateral longer than mesial; (iv) armature of peduncle of A II: long mesial tooth on 1st segment, two distal teeth on 2nd segment; (v) armature of peduncle Mxp III: two small distal teeth of ischium, longer mesial tooth and shorter distal tooth on flexor margin of merus; (vi) general patterns of armature of chela of P I: 1-3 proximal teeth on each finger, barbate lateral margin of fixed finger; (vii) general patterns of armature of propodi and dactyli of P II-IV: flexor margins of propodi with 5-8 movable spines, flexor margins of dactyli with 12-16 movable spines along entire length except most proximal part.

Table 2. Differences between Munida chathamensis and the two new New Zealand species.

\begin{tabular}{|c|c|c|c|}
\hline Characters & M. chathamensis & M. gordoni sp. nov. & M. grieveae sp. nov. \\
\hline Lateral precervical teeth & unequal & unequal & subequal \\
\hline Lateral pairs of epigastric teeth & barb & well-defined tooth & well-defined tooth \\
\hline 3rd postcervical tooth & well defined & well defined & rudimental \\
\hline Postcervical spine on branchial region & well defined & rudimental & well defined \\
\hline Granulate lateral carinae on thoracic posterior sternites & absent & absent & present \\
\hline $\begin{array}{l}\text { Longer lateral spine of lst segment of A I relative to end } \\
\text { of longer terminal spine }\end{array}$ & barely reaching & not reaching & overreaching \\
\hline 1st segment, A I ventral surface bearing & well-defined tooth & several barbs & several barbs \\
\hline 1st segment, A II with terminal tooth reaching & $2 / 3$ of 2 nd segment & $\begin{array}{l}\text { beyond end of } 3 \text { rd } \\
\text { segment }\end{array}$ & $3 / 4$ of 2 nd segment \\
\hline Mesial spine, 2nd A II segment reaching & middle of 3 rd segment & middle of $3 \mathrm{rd}$ segment & beyond A II peduncle \\
\hline Lateral spine, 2nd A II segment reaching & middle of 3 rd segment & middle of 3 rd segment & end of 3rd segment \\
\hline Terminal tooth, 3rd segment of A II peduncle & present & absent & absent \\
\hline Medial tooth of merus reaching end of same segment & yes & no & no \\
\hline Length of P I / length of Cp & 2.5 & 3.0 & 2.5 \\
\hline No. of teeth in proximal part of P I dactyl & 2 & 2 & 1 \\
\hline No. of movable spines on flexor margin of P II propodus & 8 & - & 8 \\
\hline No. of movable spines on flexor margin of P II dactyl & $12-13$ & - & $15-16$ \\
\hline No. of movable spines on flexor margin of P III propodus & 8 & 5 & $5-6$ \\
\hline No. of movable spines on flexor margin of P III dactyl & $12-13$ & 16 & 13 \\
\hline No. of movable spines on flexor margin of P IV propodus & $6-8$ & 5 & 5 \\
\hline No. of movable spines on flexor margin of P IV dactyl & $12-13$ & 16 & 12 \\
\hline
\end{tabular}

-, no data. 
However, the three species demonstrate numerous and significant differences at species level. The most important characters distinguishing $M$. gordoni sp. nov., M. grieveae sp. nov., and M. chathamensis are presented in Table 2.

\section{Etymology}

Named after Dr Janet Bradford-Grieve (NIWA), carcinologist and marine biologist, member of the Royal Society of New Zealand.

\section{DISCUSSION}

Only three species of Munida were previously reported from New Zealand. Two of them, M. gracilis Henderson, 1885 and M. gregaria Fabricius, 1793, are also widely distributed outside New Zealand waters. Both species inhabit various shelf and continental slope biotopes, their larvae constitute a common component of the plankton and are an important food source for numerous fish and birds. The only endemic New Zealand species, $M$. chathamensis, was described from a depth of about $1000 \mathrm{~m}$ in the ares of the Chatham Rise (Baba, 1974).

Samples taken by the RV 'Tangaroa' from seamounts with and without hydrothermal activity have yielded numerous specimens, some of which are closely related to M. chathamensis. These specimens exhibit high morphological diversity in characters used in species diagnoses (Baba, 1988; Macpherson, 1997, 2000). Regrettably, most new morphological forms of the Tangaroa collection are represented by only one or two specimens. Therefore, only the two most distinctive species of Munida and one species of Agononida can be described as new. Other, less distinctive morphs, which could represent further new species, can be described only when more specimens become available.

The main general biological result of this preliminary examination of the present galatheid collection is an unexpectedly high endemism and biodiversity of the seamounts around New Zealand. The NIWA collections demonstrate that many sampled seamounts harbour endemic morphs, some of which may be referred to as new species.

I have had the privilege to start this work through the courtesy of Dr N.L. Bruce who invited me to study the galatheids collected during the NIWA's seamount cruises. I am also grateful to the NIWA for research facilities, to Drs J. Bradford-Grieve and D. Gordon for their advice and the warm and friendly atmosphere around me.

The present study contributes to the NIWA's Foundation for Research, Science and Technology project 'Seamounts: their importance to fisheries and marine ecosystems' (C01X0028).

\section{REFERENCES}

Baba, K., 1969. Four new genera with their representatives and six new species of the Galatheidae in the collection of the Zoological Laboratory, Kyushu University, with redefinition of the genus Galathea. Ohmu: Occasional Papers of the Zoological Laboratory, Faculty of Agriculture, Kyushu University. Fukuoka, 2(2), $1-32$.
Baba, K., 1974. Four new species of Galatheidean Crustacea from New Zealand waters. Fournal of the Royal Society of New Zealand, 4, 381-393.

Baba, K., 1988. Chirostylid and galatheid crustaceans (Decapoda: Anomura) of the Albatross Philippine Expedition 1907-1910. Research on Crustacea, Special Number, 2, 1-203.

Baba, K., Hayashi, K. \& Toriyama, M., 1986. Decapod crustaceans from continental shelf and slope around Japan. Tokyo: Japan Fisheries Resource Conservation Association.

Baba, K. \& Saint Laurent, M. de, 1996. Crustacea Decapoda: revision of the genus Bathymunida Balss, 1914, and description of six new related genera (Galatheidae). In Résultats des campagnes MUSORSTOM, vol. 15 (ed. A. Crosnier). Mémoires du Muséum National d'Histoire Naturelle, Paris, Zoologie, 168, 433-502.

Clark, M.R., O’Shea, S., Tracey, D.M. \& Glasby, B., 1999. New Zealand region seamounts: aspects of their biology, ecology and fisheries. NIWA Client Report, WLG99/32, 107 pp.

Fabricius, J.C., 1793. Entomologia systematica emendata et aucta secundum classes, ordines, genera, species ajectis synonymis, locis, observationibus, descriptionibus. V. 2, Hafniae, viii+519 pp.

Henderson, J.R., 1885. Diagnoses of the new species of Galatheidea collected during the "Challenger" Expedition. Annals and Magazine of Natural History, 16, 407-421.

Henderson, J.R., 1888. Report on the Anomura collected by H.M.S. Challenger during the years 1873-76. Report of the Scientific Results of the Voyage of H.M.S. Challenger, Zoology, 27, 221 pp.

Keating, B.H., Fryer, P., Batiza, R. \& Boehlert, G.W., eds, 1987. Seamounts, islands, and atolls. Geological Monograph, 43, 405 p.

Macpherson, E., 1994. Crustacea Decapoda: species of the genus Munida Leach, 1820 (Galatheidae) collected during the MUSORSTOM and CORINDON cruises in the Philippines and Indonesia. In Résultats des campagnes MUSORSTOM, vol. 10 (ed. A. Crosnier). Mémoires du Muséum National d'Histoire Naturelle, Paris, Zoologie, 156, 421-442.

Macpherson, E., 1997. Crustacea Decapoda: species of the genera Agononida Baba \& de Saint Laurent, 1996 and Munida Leach, 1820 (Galatheidae) from the KARUBAR cruise. In Résultats des campagnes MUSORSTOM, vol. 16 (ed. A. Crosnier and P. Bouchet). Mémoires du Muséum National d'Histoire Naturelle, Paris, Zoologie, 172, 597-612.

Macpherson, E., 2000. Crustacea Decapoda: species of the genera Crosnierita Macpherson, 1998, Munida Leach, 1820, and Paramunida Baba, 1998 (Galatheidae) collected during the MUSORSTOM 9 cruise to the Marquesas Islands. In Résultats des campagnes MUSORSTOM, vol. 21 (ed. A. Crosnier). Mémoires du Muséum National d'Histoire Naturelle, Paris, Zoologie, A, 184, 415-423.

Miyake, S. \& Baba, K., 1967. Descriptions of new species of galatheids from the western Pacific. Fournal of the Faculty of Agriculture, Kyushu University, 14, 203-212.

Rogers, A.D., 1994. The biology of seamounts. Advances in Marine Biology, 30, 305-350.

Rowden, A.A., O'Shea, S. \& Clark, M.R., 2002. Biodiversity of seamounts on the northern Chatham Rise. Unpublished Report, available NIWA, Wellington.

Vereshchaka, A.L., 1995. Macroplankton in the near-bottom layer of the continental slopes and seamounts. Deep-Sea Research I, 42, 1639-1668.

Vereshchaka, A.L., 2000. The genus Sergia: taxonomy, systematics, and distribution. Galathea Report, 18, 69-207.

Submitted 12 January 2004. Accepted 11 January 2005. 